\title{
Research on Transient Power Quality of Large-capacity Electric Arc Furnace
}

\author{
Liu Yang ${ }^{1}$, Qinyue Tan ${ }^{1, *}$, Di Xiong ${ }^{1}$ and Zhengguang Liu ${ }^{1}$ \\ 1 College of Water Resources and Architectural Engineering, Northwest A\&F University, Shaanxi 712100, China; \\ yl1195431826@163.com (L.Y); 18821712577@163.com (D.X); 17792617508@163.com (Z. L); \\ * Correspondence: qinyuetan@nwsuaf.edu.cn ;
}

\begin{abstract}
The overrun of transient power quality index caused by the large-capacity electric arc furnace (EAF) has become a prominent problem affecting the safe and stable operation of the power system. (1) In this paper, the relationship between arc furnace voltage and current is derived based on the different stages of arc combustion, and the random variation of chaotic phenomenon of the arc voltage are simulated. Established an EAF model suitable for the study of transient power quality problems. (2) Take 50t AC EAF as an example to analyze the reactive power impact and the influence on the point of common coupling (PCC) voltage caused by the three-phase short circuit of the electrode. The results show that the experimental results are consistent with the theoretical analysis, verifying the correctness and effectiveness of the model. (3) When the three-phase short-circuit occurs, the reactive power impact is nearly 6 times that of normal operation, the short-circuit current is 2.66 times that of normal operation, and the effective value of the PCC voltage has dropped by $40.37 \%$, which provides a theoretical basis for real-time compensation of impulsive reactive power and improvement of the transient power quality of the EAF.
\end{abstract}

Keywords: electric arc furnace (EAF); non-linear; transient power quality; reactive power impact; voltage sag

\section{Introduction}

Non-linear load is the main pollution source of power quality. Among many non-linear loads, AC electric arc furnace (EAF) is the most complicated and random pollution source. Steady-state power quality problems caused by EAF have been the focus of research, such as voltage fluctuation [1,2], harmonic [2], and three-phase unbalance [3]. However, in the operation of the EAF, there are also transient power quality problems, such as the voltage sag caused by the short-circuiting of the electrodes of the EAF. In the articles on the voltage problem of electric arc furnace, most of them study voltage fluctuation [4-5], and rarely study voltage sag. Some papers attribute the voltage changes caused by short-circuit electrodes to voltage fluctuations, which is not very accurate.

Many papers have established models to study the steady-state power quality of EAF [7-19]. Ref. [9] and Ref. [10] study the internal and external factors that affect arc resistance according to the physical mechanism of the EAF during the cycle of operation to obtain the arc resistance expression. Ref. [11] and Ref. [12] fits the volt-ampere characteristic curve of the EAF, and considers the change of the active power to obtain the expression of arc voltage with respect to arc current. Ref. [13] and Ref. [14] combine exponential model and hyperbolic model to describe the expression of electric arc furnace voltage with respect to current. Ref. [15] and Ref. [16] list the expressions of arc resistance according to the volt-ampere characteristic curve of the EAF. Ref. [17] and Ref. [18] establish an EAF model by using the law of energy conservation to list the differential equations. Ref. [19] believes that the voltage fluctuation caused by the EAF is chaotic. In addition, there are modeling for harmonic analysis [20] and modeling of electric arc furnace with neural network [21-23]. there are some limitations such as need to initial conditions for solving the differential equations, balanced operating condition of the three phases of the EAF and use of sophisticated mathematical equations for the estimation of the arc model.

According to the different states of arc combustion, this article lists the mathematical models of the EAF in different combustion stages combined with the hyperbolic model and the exponential model. Then, white noise is added to simulate the random change of the arc and the Chua's circuit is used to modulate the arc voltage to obtain the final EAF model. The model does not need to solve complex differential equations, is simple and accurate. What's more, it does not require initial conditions, has strong portability and wide applicability. It can simulate the electric arc furnace in any arc state, and is suitable for studying the steady-state power quality of the EAF as well as the transient power 
quality of the EAF. Finally, the model is used to simulate the three-phase short circuit, the most serious short-circuit phenomenon of the EAF, and compare with the analysis and calculation results.

\section{EAF model}

The EAF melts steel by the heat generated by arc combustion, and the arc impedance is nonlinear and time-varying. It is difficult to obtain the arc impedance expression simply and accurately. However, when studying the influence of the EAF on the power quality of the power supply system, we do not need to obtain a specific arc impedance expression, as long as the external characteristics of the EAF can be accurately simulated. The arc is divided into three stages during the operation of the EAF, and the external characteristics of each stage are different.

A. The stage of arc starting

In the arc furnace, the arc changes from nothing to the burning state, the arc voltage rises from zero to the reignition voltage $\mathrm{U}_{i g}$, and the arc ignites and enters the combustion stage. At this stage, there is no arc in the EAF. However, a small leakage current exists, which flows through the foamy slag parallel with the arc, the foamy slag is assumed to be a constant resistance $R$ [15].

B. The stage of arc combustion

After the arc voltage rises to the reignition voltage, the arc enters the combustion stage. With the continuous increase of arc current and temperature, the ability of the electrode to emit electrons and the ionization ability of the surrounding gas are enhanced. Therefore, the electrical conductivity of the gas increases and the arc resistance decreases. Under the same arc length, the arc voltage required to maintain the arc combustion decreases. The arc voltage decreases with the increase of the arc current, and presents a hyperbolic relationship at this stage [13,14].

C. The stage of arc extinguishing

In the combustion stage, the arc voltage decreases with the increase of the arc current. After the arc voltage drops to the arc extinguishing voltage, the arc extinguishes and enters the arc extinguishing stage. In the case of a certain arc length, the arc voltage gradually decreases to zero as the arc current decreases. The relationship between arc voltage and current at this stage is described by an exponential function [13,14].

Therefore, the relationship between arc voltage and arc current is:

$$
u(i)= \begin{cases}R i & |i| \leq U_{i g} / R \\ V_{0}+\left(\frac{C}{i+D}\right) & \frac{d i}{d t}>0,|i|>U_{i g} / R \\ V_{0}\left(1-e^{-i / \tau}\right) & \frac{d i}{d t}<0,|i|>U_{i g} / R\end{cases}
$$

$V_{0}$ is the threshold magnitude to which the electric arc voltage approaches as current increases, it is related to the arc length. The constants $C$ and $D$ are related to arc power and arc current, respectively. $l$ is the arc length $a$ is the sum of the potential drops in the anode and cathode regions, taking $a=40 \mathrm{~V}, b$ is the potential gradient in the arc column, $\mathrm{b}=10 \mathrm{~V} / \mathrm{cm} . \tau$ is a current constant used to model the steepness of the positive and negative phases of the arc current.

$$
V_{0}=a+b l
$$

Equation (1) describes the relationship between arc voltage and arc current under the condition of a certain arc length. However, the surface of the slag smelted by the EAF is not even, so the arc length is constantly changing, and the change is random. Generally, white noise is used to simulate the random change of the arc length.

$$
l=l_{0}(1+m N(t))
$$

In actual operation, the load of the three-phase EAF is asymmetrical, and different $l_{0}$ can be set to model the load asymmetry of the three-phase EAF. $N(t)$ is a band-limited white noise.

In previous studies, the voltage fluctuation caused by the electric arc furnace was proved to be chaotic, so in order to simulate the voltage fluctuation phenomenon more accurately, a chaotic signal was added to modulate the arc voltage. The chaotic signal is simulated by Chua's circuit with asymmetric nonlinear resistance.

$$
U_{\text {arc }}=u(i) \times\left(1+n u_{\text {chaotic }}\right)
$$


$\mathrm{U}_{\text {arc }}$ is the arc voltage, $u$ chaotic is the low-frequency voltage chaotic signal output by Chua's circuit, $n$ is the ratio of the peak value of the low-frequency voltage chaotic signal to the peak value of the arc voltage. Chua's circuit diagram is shown in Figure 1.

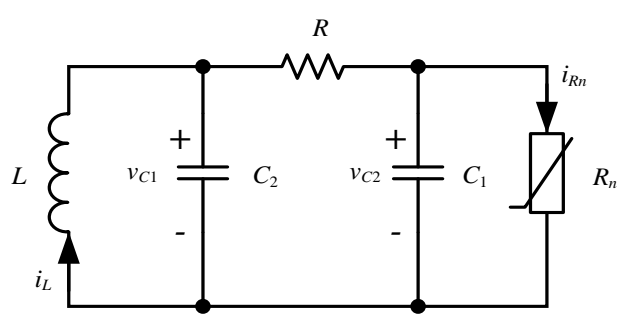

Figure 1. The diagram of Chua's circuit.

\section{Simulation of EAF with power system}

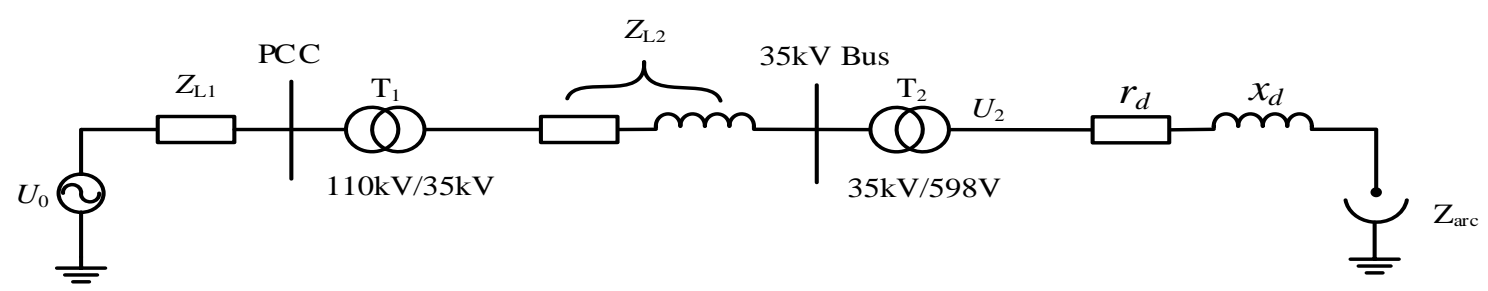

Figure 2. the equivalent circuit diagram of a single-phase power supply system for a 50t AC EAF

Figure 2 is the equivalent circuit diagram of a single-phase power supply system for a 50t AC electric arc furnace. Where $\mathrm{Z}_{\mathrm{L} 1}$ is the line impedance from the power supply to the PCC, $\mathrm{Z}_{\mathrm{L} 2}$ is the line impedance and reactor impedance from PCC to $35 \mathrm{kV}$ bus, $r_{d}$ and $x_{d}$ are the resistance and reactance of the EAF short network, $\mathrm{U}_{0}$ and $\mathrm{U}_{2}$ are the power supply voltage and the secondary side voltage of the furnace transformer respectively, Zarc is the arc impedance. The parameters of EAF are shown in Table 1, and the parameters of EAF power supply system are shown in Table 2.

Table 2. The parameters of EAF and power supply system.

\begin{tabular}{cccc}
\hline parameters & value & parameters & value \\
\hline $\mathrm{C}$ & 350000 & Rated voltage of T1 $(\mathrm{kV})$ & $220 / 35$ \\
$\mathrm{D}$ & 5000 & Rated capacity of T1 $(\mathrm{MVA})$ & 63 \\
$\tau$ & 10000 & Short-circuit impedance of T1 & $6.3 \%$ \\
$l_{0}(\mathrm{~cm})$ & 25 & Load loss of T1 $(\mathrm{kW})$ & 270 \\
$\mathrm{U}_{0}(\mathrm{kV})$ & 220 & $X_{\mathrm{L} 2}(\Omega)$ & 3.196 \\
$X_{\mathrm{L} 1}(\Omega)$ & 1.452 & Rated voltage of T2 $(\mathrm{MVA})$ & $35 / 0.996$ \\
Rated capacity of T2 $(\mathrm{MVA})$ & 50 & The resistance of short network $(\mathrm{m} \Omega)$ & $\mathrm{rd}_{\mathrm{d}}=0.4077$ \\
Load loss of T2 $(\mathrm{kW})$ & 250 & & $\mathrm{X}_{\mathrm{d}}=2.9786$ \\
\hline
\end{tabular}

The 50t AC EAF is simulated using the model proposed in this paper. Figure 3 is the EAF volt-ampere characteristic curve without random modules and chaotic circuits, Figure 4 (a) is the waveforms of arc furnace voltage and current without the random module and chaos circuit, and Figure 4 (b) is the waveforms of arc furnace voltage and current after adding the random module and chaos circuit. 


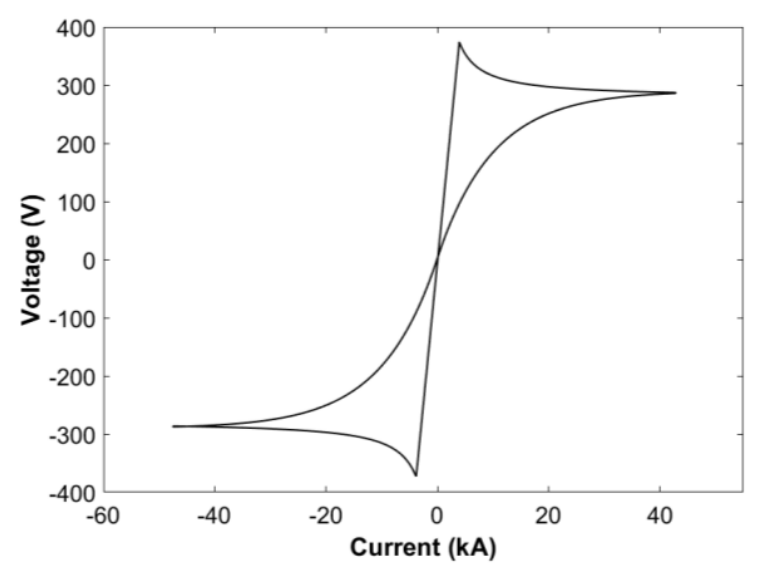

Figure 3. the volt-ampere characteristic curve of EAF without random modules and chaotic circuits.

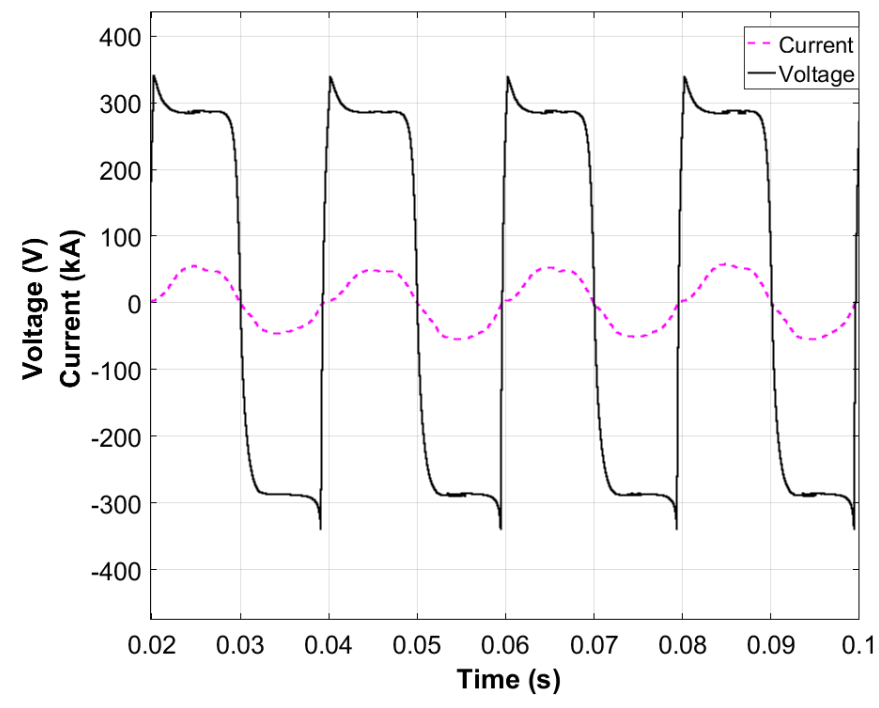

(a)

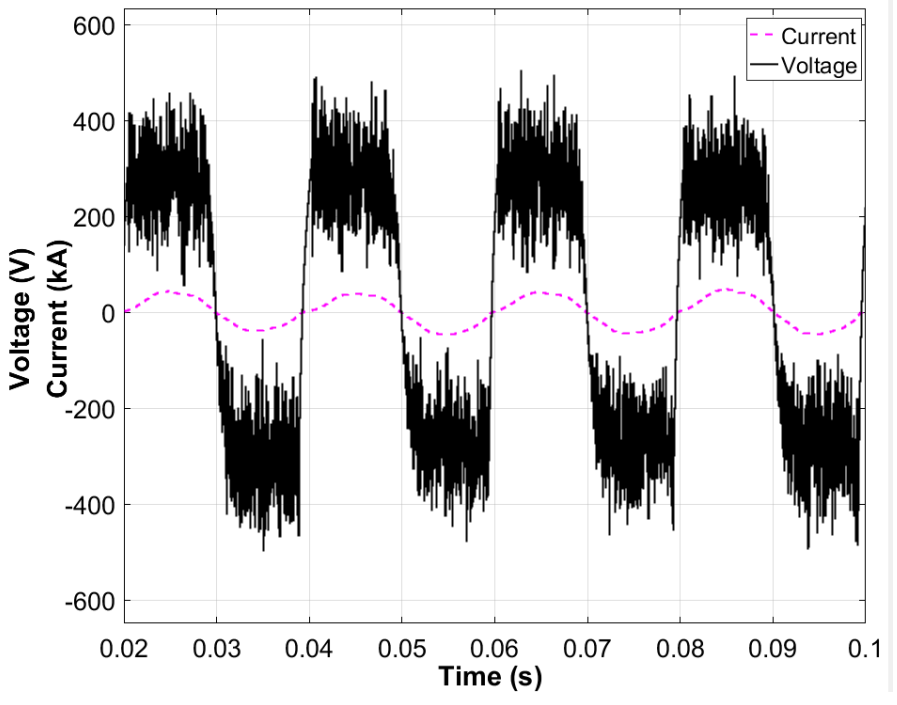

(b)

Figure 4. The waveforms of EAF voltage and current: (a) Without random modules and chaotic circuits; (b) Adding random modules and chaotic circuits.

The volt-ampere characteristic curve in Figure 3 accurately simulates the relationship between the voltage and current of the EAF at different stages of the arc. Figure 4(a)shows that the waveform of the EAF voltage is similar to a square wave, and a sharp wave appears after each current zero-crossing. The maximum value of the sharp wave is the reignition voltage. After adding random modules and Chua's circuit, voltage fluctuations can be clearly seen in Figure 4(b). The simulated voltage waveform, current waveform and volt-ampere characteristic curve are similar to those in the actual operation. Therefore, the model can accurately simulate the external characteristics of the EAF at different stages for studying the influence on the power quality of the power supply system. Moreover, the model is established based on the different combustion states of the arc, and the short-circuit or open-circuit of the arc corresponds to different combustion states, so it can be used for the study of transient power quality problems caused by EAF. By changing the parameters in the relationship between arc voltage and current, it can be used to simulate different EAF.

\section{Analysis and Simulation of Three-phase Short Circuit in EAF}

When the arc furnace electrode is short-circuited, a large short-circuit current is generated, which causes a reactive power impact on the power grid, and the PCC voltage sag. After a short circuit occurs, the electrode adjustment system will adjust the electrode position to restore the EAF to normal. Generally, the duration of a short-circuit fault in the EAF is $0.01 \mathrm{~s}$ to $0.02 \mathrm{~s}$. The most serious short-circuit phenomenon should be simultaneous short-circuit of the three phase electrodes. Of course, the probability of a three-phase short-circuit in modern EAF is small, but the situation is serious, so it cannot be ignored. 
$r_{0}+j x_{0}$ is the sum of system impedance, line impedance, reactor impedance, and transformer impedance converted to the secondary side of the furnace transformer. When a three-phase short circuit occurs in an EAF, the three-phase circuit is symmetrical and $\mathrm{U}_{a r}=0$.

The arc voltage is derived from the arc current to obtain the arc furnace impedance.

$$
Z_{\text {arc }}= \begin{cases}R & |i| \leq U_{i g} / R \\ \frac{V_{0}}{i}+\frac{C_{a}}{(D+i)^{2}} & \frac{d i}{d t}>0,|i|>U_{i g} / R \\ \frac{V_{0}}{\tau} e^{-i / \tau} \quad \frac{d i}{d t}<0,|i|>U_{i g} / R\end{cases}
$$

Arc current: $I=\frac{U_{2} / \sqrt{3}}{\sqrt{\left(r_{0}+r_{d}+Z_{a r c} \cdot \cos \varphi\right)^{2}+\left(x_{0}+x_{d}+Z_{a r c} \cdot \sin \varphi\right)^{2}}}$

Reactive power: $Q=3 I^{2} \cdot\left(x_{0}+x_{d}+Z_{\text {arc }} \cdot \sin \varphi\right)$,

Active power: $P=3 I^{2} \cdot\left(r_{0}+r_{d}+Z_{\text {arc }} \cdot \cos \varphi\right)$

The voltage of PCC: $U_{P C C}^{\prime}=I^{\prime} \times\left(r_{0}+x_{0}\right)$,

The amplitude of voltage sag at PCC: $\Delta U=\frac{P R+Q X}{U}$

Table 3 is the calculation results and simulation results when a three-phase short circuit occurs in the EAF., Figure 5 is the waveforms of the voltage and current at the PCC, respectively, and Figure 8 is the waveforms of the active power and the reactive power at the PCC When a three-phase short circuit occurs in the arc furnace at $0.04 \mathrm{~s}-0.05 \mathrm{~s}$.

Table 3. The calculation results and simulation results when a three-phase short circuit occurs in the EAF

\begin{tabular}{ccc}
\hline Parameters & calculation results & simulation results \\
\hline Short-circuit current on secondary side of T2 (kA) & 45.76 & 44.83 \\
Short-circuit current on 35kV bus (kA) & 1.32 & 1.29 \\
Short-circuit current on PCC (A) & 420.38 & 409.84 \\
$U_{P C C}^{\prime}(\mathrm{kV})$ & 36.45 & 34.6 \\
$Q^{\prime}(\mathrm{MVA})$ & 42.53 & 36.71 \\
\hline
\end{tabular}

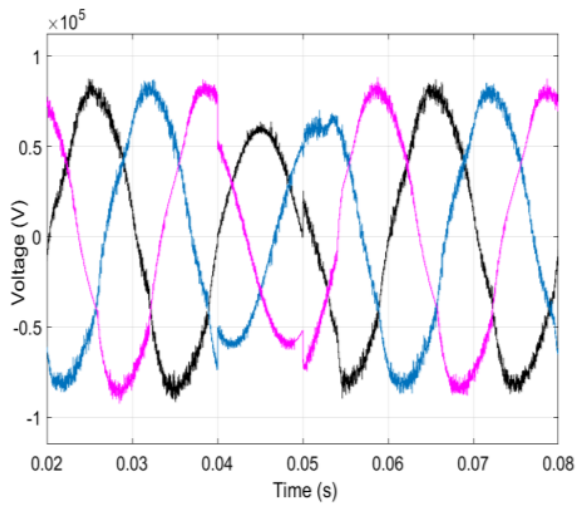

(a)

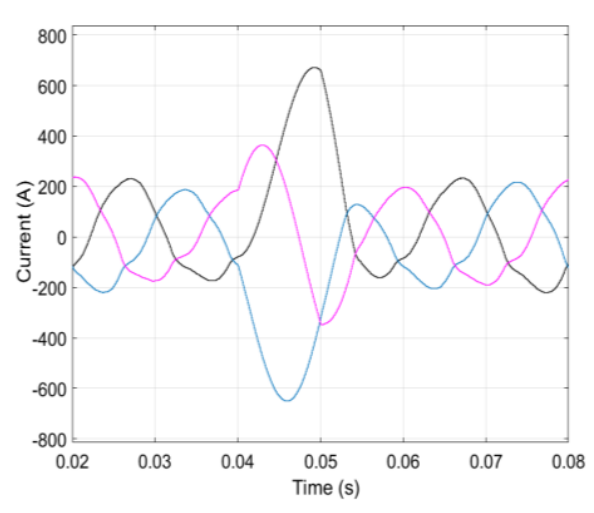

(b)

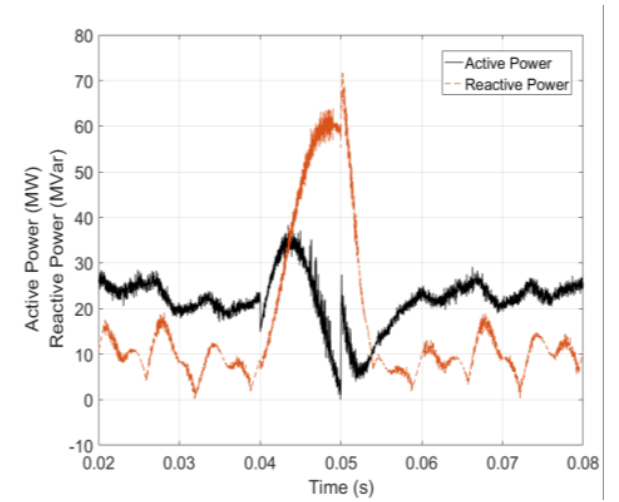

(c)

Figure 5. when a three-phase short circuit occurs in the EAF. (a) The waveform of voltage; (b) The waveform of current;(c) The waveforms of active power and reactive power

It can be seen from Table 3 that the error between the calculation results of short-circuit current, reactive power and PCC voltage and the simulation results is very small when a three-phase short-circuit occurs, indicating that the model can be used to simulate the short-circuit phenomenon of EAF and analyze the transients power quality caused by EAF. 
It can be seen from Table 3 and Figure 5 that when a three-phase short circuit occurs, a large current inrush and reactive power impact are generated. The short-circuit current is 2.66 times the current during normal operation, the reactive power has increased from a dozen MVA to 63.85MVA, the effective value of the PCC phase voltage has dropped from $58.02 \mathrm{kV}$ to $34.6 \mathrm{kV}$, a decrease of $40.37 \%$ drop, and the peak value of the PCC phase voltage has dropped from $87.79 \mathrm{kV}$ to $64.09 \mathrm{kV}$, a decrease of $27 \%$. The drop of PCC voltage belongs to the phenomenon of voltage sag in transient power quality.

\section{Discussion}

The voltage problem caused by the EAF has always been a hot research topic. The random change of arc length during the operation of the EAF causes the voltage fluctuation of the PCC, many papers have put forward solutions to the voltage fluctuation problem. However, the drop of voltage caused by the short-circuit problem of the EAF is very large, which is no longer a voltage fluctuation, but a voltage sag.

The International Institute of Electrical and Electronic Engineers (IEEE) defines voltage sag as the phenomenon that the effective value of the supply voltage drops rapidly to $90 \% \sim 10 \%$ of the rated value and the duration is 0.5 cycles $\sim 1$ minute. In the latter stages of the melting period, short-circuiting often occur in the EAF because the furnace material collapses in contact with the electrodes. After the electrode control system detects the short circuit, it will quickly raise the electrode to restore the normal operation of the EAF. The short-circuit time of the electrode is about 0.01 0.02s. It can be seen from the simulation results that the EAF short circuit causes the PCC voltage to drop by $40.37 \%$, which meets the defined range of voltage sag. Obviously, the short-circuiting of the electrode causes the voltage of the point of common coupling (PCC) to fall, which is a voltage sag. Voltage sags are more harmful to the grid than voltage fluctuations, so we need to arouse our attention to improve this phenomenon

\section{Conclusions}

This paper established an EAF model for steady-state power quality problems and transient power quality problems. The results shown:

(1) The new EAF model can simulate the external characteristics of EAF at different stages accurately without initial conditions and complex differential equations. This model will be a new way for analyzing steady-state power quality problems and transient power quality problems.

(2) The phenomenon of short circuits and open circuits occur frequently in EAF during the melting period. When these phenomena occur, the impact on the power quality of PCC is even more serious. Therefore, it is necessary to analyze the impact of PCC power quality under different conditions and make improvements more targeted.

(3) The drop of PCC voltage caused by the short circuit of EAF is voltage sag rather than voltage fluctuation. The transient power quality problem is more complicated than the steady-state power quality problem, which needs further research.

Author Contributions: Conceptualization, Q.T.; methodology, Q.T. and L.Y.; software, L.Y.; validation, Q.T., L.Y. and D.X.; formal analysis, L.Y.; investigation, L.Y.; resources, Q.T.; data curation, D.X.; writing - original draft preparation, L.Y. and Z.L.; writingreview and editing, Q.T., L.Y. and Z.L.; visualization, L.Y.; supervision, Q.T.; project administration, Q.T.; funding acquisition, Q.T. All authors have read and agreed to the published version of the manuscript.

Funding: This research was funded by THE NATIONAL NATURE SCIENCE FOUNDATION OF CHINA, grant number 51577157, and in part by THE SHAANXI PROVINCE NATURAL SCIENCE BASIC RESEARCH PROGRAM, grant number 2019JM-357.

Conflicts of Interest: The authors declare no conflict of interest.

\section{References}

1. Lukasik, Z.; Olczykowski, Z. Estimating the impact of arc furnaces on the quality of power in supply systems. Energies 2020, 13, 1462.

2. Liu, Y. W.; Rau, S. H.; Wu, C. J. Improvement of power quality by using advanced reactive power compensation. IEEE Trans. Ind. Appl. 2018, 54, 18-24.

3. Naderipour, A.; Abdul-Malek, Z.; Gandoman, F. H. Optimal designing of static var compensator to improve voltage profile of power system using fuzzy logic control. Energy 2019, 192, 1-17.

4. Horton, R.; Haskew, T.A.; Burch, R.F., IV. A time-domain ac electric arc furnace model for flicker planning studies. IEEE Trans. Power Deliv. 2017, 24, 1450-1457.

5. Chang, G.W.; Lin, S.; Chen, Y.; Lu, H.; Chang, Y. An advanced EAF model for voltage fluctuation propagation study. IEEE Trans. Power Deliv. 2017, 32, 980-988.

6. Yu, J. H.; Kuan Hung Chen, Po Yi Huang, et al. Electric arc furnace voltage flicker analysis and prediction. IEEE Trans. on instrumentation and measurement 2011, 60, 3360-3368. 
7. Cano-Plata, E.A.; Ustariz-Farfan, A.J.; Soto-Marin, O.J. Electric arc furnace model in distribution systems. IEEE Trans. Ind. Appl. 2015, 51, 4314-4320.

8. Mehdi, T. E.; Behrooz, V. A new stochastic model of electric arc furnace based on hidden markov model: A study of its effects on the power system. IEEE Trans. Power Deliv. 2012, 27, 1893-1901.

9. Liu, X. H.; Yang, X. Y. Research on frequency domain method of harmonic analysis of electric system of arc furnace. Proceedings of the CSEE 2006, 26, 30-35.

10. Liu, X. H.; Zhao, G.; Yu, J. J. Simulation research on the influence of electric arc furnace nonlinear characteristics on power supply network. Proceedings of the CSEE 2004, 24, 30-35.

11. Wang, Y. F.; Jiang, J. G. A novel chaotic model of ac electric arc furnace for power quality study. Proceedings of the CSEE 2008, 28, 106-110.

12. Qi, B.R.; Xiao, X. N. Model and simulation of electric arc furnace for voltage fluctuation research. Transactions of China Electrotechnical Society 2000, 15, 31-35.

13. Banejad, M.; Hooshmand, R.; Torabian, E. M. Exponential-Hyperbolic Model for Actual Operating Conditions of Three Phase Arc Furnaces. American Journal of Applied Sciences 2009, 6, 1539-1547.

14. Bhonsle, D. C.; Kelkar, R. B. Analyzing power quality issues in electric arc furnace by modeling. Energy 2016, 115, 830-839.

15. Zheng, T. X.; Makram, E. B. An adaptive arc furnace model. IEEE Trans. Power Deliv. 2020, 15, 931-939.

16. Teklic, A. T.; Filipovic-Grcic, B.; Pavic, I. Modelling of three-phase electric arc furnace for estimation of voltage flicker in power transmission network. Electric Power Systems Research 2017, 146, 218-227.

17. Alonso, M. A. P.; Donsion, M. P. An improved time domain arc furnace model for harmonic analysis. IEEE Trans. Power Syst. 2004, 19, 367-373.

18. Wang, J.; Shu, H. C.; Lin, M.; Chen, C. Y. Modeling and simulation of AC arc furnace for dynamic power quality studies. Transactions of China Electrotechnical Sociaty 2003, 18, 53-58.

19. Wang, Y. F.; Hao, L.; Hua, X. Study of a flexible power supply system with STATCOM based on a new dynamic EAF model, 2016 IEEE 8th International Power Electronics and Motion Control Conference (IPEMC 2016 - ECCE Asia). Hefei, China, 22 May-25 May 2016.

20. Xu, H. B.; Shao, Z. G.; Chen, F. X. Data-Driven compartmental modeling method for harmonic analysis-a study of the electric arc furnace. Energies 2019, 12, 4378.

21. Gajic, D.; Savic-Gajic, I.; Savic, I.; Georgieva, O.; Gennaro, S.D. Modelling of electrical energy consumption in an electric arc furnace using artificial neural networks. Energy 2016, 108, 132-139.

22. Chang, G. W.; Shi, M. F.; Chen, Y. Y.; Liang, Y. J. Hybrid wavelet transform and neural-network-based approach for modelling dynamic voltage-current characteristics of electric arc furnace. IEEE Trans. Power Deliv. 2014, 29, 815-824.

23. Raul, G. S.; Javier, V. C.; Fernando, M. C.; Omar, L. G.; Jaime, O. A. Electric arc furnace modeling with artificial neural networks and arc length with variable voltage gradient. Energies 2017, 10, 1424. 